\title{
A subclinical high tricuspid regurgitation pressure gradient independent of the mean pulmonary artery pressure is a risk factor for the survival after living donor liver transplantation
}

Yosuke Saragai ${ }^{1}$, Akinobu Takaki ${ }^{*}$, Yuzo Umeda², Takashi Matsusaki ${ }^{3}$, Tetsuya Yasunaka ${ }^{1}$, Atsushi Oyama', Ryuji Kaku ${ }^{3}$, Kazufumi Nakamura ${ }^{4}$, Ryuichi Yoshida², Daisuke Nobuoka ${ }^{2}$, Takashi Kuise ${ }^{2}$, Kosei Takagi ${ }^{2}$, Takuya Adachi ${ }^{1}$, Nozomu Wada', Yasuto Takeuchi ${ }^{1}$, Kazuko Koike ${ }^{1}$, Fusao Ikeda', Hideki Onishi ${ }^{1}$, Hidenori Shiraha', Shinichiro Nakamura', Hiroshi Morimatsu ${ }^{3}$, Hiroshi Ito ${ }^{4}$, Toshiyoshi Fujiwara ${ }^{2}$, Takahito Yagi ${ }^{2}$ and Hiroyuki Okada ${ }^{1}$

\begin{abstract}
Background: Portopulmonary hypertension (POPH) is characterized by pulmonary vasoconstriction, while hepatopulmonary syndrome (HPS) is characterized by vasodilation. Definite POPH is a risk factor for the survival after orthotopic liver transplantation $(\mathrm{OLT})$, as the congestive pressure affects the grafted liver, while subclinical pulmonary hypertension (PH) has been acknowledged as a non-risk factor for deceased donor OLT. Given that PH measurement requires cardiac catheterization, the tricuspid regurgitation pressure gradient (TRPG) measured by echocardiography is used to screen for PH and congestive pressure to the liver. We investigated the impact of a subclinical high TRPG on the survival of small grafted living donor liver transplantation (LDLT).
\end{abstract}

Methods: We retrospectively analyzed 84 LDLT candidates. Patients exhibiting a TRPG $\geq 25 \mathrm{mmHg}$ on echocardiography were categorized as potentially having liver congestion (subclinical high TRPG; $n=34$ ). The mean pulmonary artery pressure (mPAP) measured after general anesthesia with $\mathrm{FIO}_{2} 0.6\left(\mathrm{mPAP}-\mathrm{FIO}_{2} 0.6\right)$ was also assessed. Patients exhibiting $\mathrm{pO}_{2}<80 \mathrm{mmHg}$ and an alveolar-arterial oxygen gradient $\left(\mathrm{AaDO}_{2}\right) \geq 15 \mathrm{mmHg}$ were categorized as potentially having HPS (subclinical HPS; $n=29$ ). The clinical course after LDLT was investigated according to subclinical high TRPG.

Results: A subclinical high TRPG $(p=0.012)$ and older donor age $(p=0.008)$ were correlated with a poor 40-month survival. Although a higher mPAP-FIO 20.6 was expected to correlate with a worse survival, a high $\mathrm{MPAP}-\mathrm{FIO}_{2} 0.6$ with a low TRPG was associated with high frequency complicating subclinical HPS and a good survival, suggesting a reduction in the $\mathrm{PH}$ pressure via pulmonary shunt.

Conclusion: In cirrhosis patients, mPAP-FIO 20.6 may not accurately reflect the congestive pressure to the liver, as the pressure might escape via pulmonary shunt. A subclinical high TRPG is an important marker for predicting a worse survival after LDLT, possibly reflecting congestive pressure to the grafted small liver.

Keywords: Hepatopulmonary syndrome, Living donor related liver transplantation, Portopulmonary hypertension, Tricuspid regurgitation pressure gradient

\footnotetext{
* Correspondence: akitaka@md.okayama-u.ac.jp

'Department of Gastroenterology and Hepatology, Okayama University

Graduate School of Medicine, Dentistry and Pharmaceutical Sciences, 2-5-1

Shikata-cho, Kita-ku, Okayama 700-8558, Japan

Full list of author information is available at the end of the article
}

(c) The Author(s). 2018 Open Access This article is distributed under the terms of the Creative Commons Attribution 4.0 International License (http://creativecommons.org/licenses/by/4.0/), which permits unrestricted use, distribution, and reproduction in any medium, provided you give appropriate credit to the original author(s) and the source, provide a link to the Creative Commons license, and indicate if changes were made. The Creative Commons Public Domain Dedication waiver (http://creativecommons.org/publicdomain/zero/1.0/) applies to the data made available in this article, unless otherwise stated. 


\section{Background}

End-stage liver cirrhosis is often complicated with pulmonary capillary disorders. The most commonly found pulmonary vascular complication is hepatopulmonary syndrome (HPS), in which the pulmonary arteries dilate, resulting in arterial deoxygenation (an increased alveolararterial oxygen gradient $\left[\mathrm{AaDO}_{2}\right]$ with or without hypoxemia) [1]. Although not frequent, occasional reports of portopulmonary hypertension (POPH), in which the pulmonary arteries thicken, resulting in pulmonary hypertension (PH), have been described. The criteria for diagnosing $\mathrm{POPH}$ are $\mathrm{PH}$ (defined by a mean pulmonary artery pressure $[\mathrm{mPAP}]>25 \mathrm{mmHg}$ at rest via right heart catheterization) and high pulmonary vascular resistance without complicating left heart failure. These criteria indicate that $\mathrm{POPH}$ is a form of pulmonary hypertension not due to left ventricular heart failure in portal hypertensive patients. The prevalence of HPS in patients with cirrhosis ranges from 10 to $30 \%$, while that of $\mathrm{POPH}$ ranges from 5 to $10 \%$ [2]. Both of these complications significantly worsen the prognosis and quality of life [3].

Given that HPS can be resolved after orthotopic liver transplantation (OLT) even when hypoxemia is severe $\left(\mathrm{PaO}_{2}<50 \mathrm{mmHg}\right)$, the implications for OLT are understood to apply not only with deceased donor LT (DDLT) but also living donor related LT (LDLT). However, the post-OLT course of POPH-complicated patients is often unsatisfactory, and severe (mPAP > 45 to $50 \mathrm{mmHg}$ ) patients are considered absolutely contraindicated for OLT. The International Liver Transplant Society Practice Guidelines indicate that, unlike HPS, there are no data to support the concept that POPH (treated or untreated) should be an indication for OLT [4]. Several clinical studies have suggested that if $\mathrm{mPAP}$ is $<35 \mathrm{mmHg}$, then the perioperative mortality does not increase $[5,6]$. Furthermore, the Practice Guidelines recommend that patients with $\mathrm{mPAP}<35 \mathrm{mmHg}$ be indicated for OLT, and PAtargeted therapy should be initiated in patients with mPAP $\geq 35 \mathrm{mmHg}$ [4]. However, almost all of the patients in these articles had received DDLT, and no such analyses have been performed for LDLT patients. Given that left or right lobe LDLT grafts are smaller than DDLT grafts, PHinduced hepatic venous pressure might result in a strong congestive impact on the LDLT grafted liver.

The objective of the present study was to investigate the impact of cirrhosis-related cardio-pulmonary complications on the LDLT survival. Although patients with confirmed POPH and HPS are rare, those with mild pulmonary hypertension and mild HPS are more common. Given that right heart catheterization is not performed for all patients during the pre-operative investigation, the tricuspid regurgitation pressure gradient (TRPG) measured by transthoracic echocardiography (TTE) was adopted to estimate the $\mathrm{PH}$-related congestive pressure in the transplanted liver. The peak systolic pressure gradient between the right ventricle (RV) and the right atrium (RA) can be estimated using the peak systolic TRPG [7]. The TRPG is calculated from the peak velocity of the tricuspid regurgitation (TR) measured by continuous-wave Doppler echocardiography using the modified Bernoulli equation [8].

The risk factors associated with the 3-month, 1-year, and 40-month survival were investigated.

\section{Methods \\ Subjects}

The study group consisted of 84 retrospectively analyzed liver cirrhosis patients who received LDLT at our hospital (Table 1). All patients were recruited at the Clinic of Gastroenterology and Hepatology, Okayama University Hospital, from December 2008 to September 2015, indicating that all patients were followed for longer than 1 year. Definitely diagnosed HPS before OLT was noted in only one patient, and POPH before OLT was also noted in only one patient. The definitively diagnosed POPH patients received specific treatment with prostaglandin I2 and showed a normal range of TRPG and mPAP at LDLT.

Informed consent was obtained from each patient included in the study, and the study protocol conformed to the ethical guidelines of the 1975 Declaration of Helsinki as reflected in the approval by the ethics committee at Okayama University Hospital. After obtaining the patients' written informed consent, a detailed medical questionnaire was completed by the doctors.

Definitions of subclinical HPS and a subclinical high TRPG All of the patients underwent an arterial blood gas analysis and TTE before OLT as pre-operative screening. The patients were classified as having subclinical HPS when they exhibited elevated $\mathrm{AaDO}_{2}$ levels $(>15 \mathrm{mmHg}$ ) and decreased $\mathrm{PaO} 2$ levels $(<80 \mathrm{mmHg}$ ) according to the definition by a European Respiratory Society task force [9]. If a patient exhibited subclinical HPS, perfusion lung scanning using technetium-99 m-labeled macroaggregated albumin ([99 m]Tc-MAA) scintigraphy was performed to diagnose definite HPS. There was only one patient who exhibited definite HPS. The patients were classified as having a subclinical high TRPG when they exhibited a relatively elevated TRPG of $\geq 25 \mathrm{mmHg}$ according to the median TRPG levels before LDLT. The TRPG data were available from 76 patients. If a patient exhibited a subclinical high TRPG, the peak TR velocity was assessed to select the patients requiring further examinations according to the 2015 ESC/ERS guidelines for the diagnosis and treatment of pulmonary hypertension [7]. There was only one patient who exhibited definite $\mathrm{POPH}$ requiring anti-PH treatment. 
Table 1 Patient characteristics

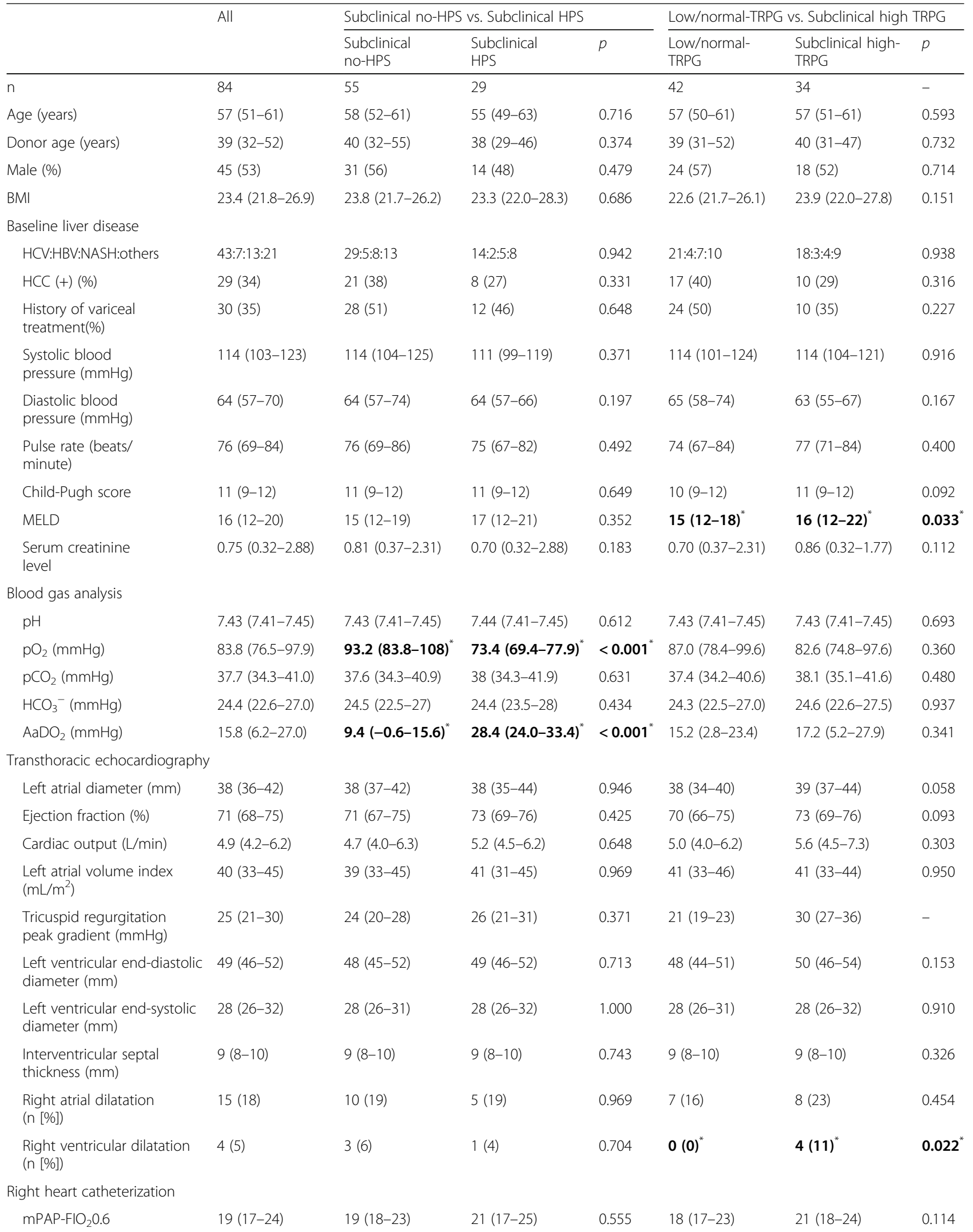


Table 1 Patient characteristics (Continued)

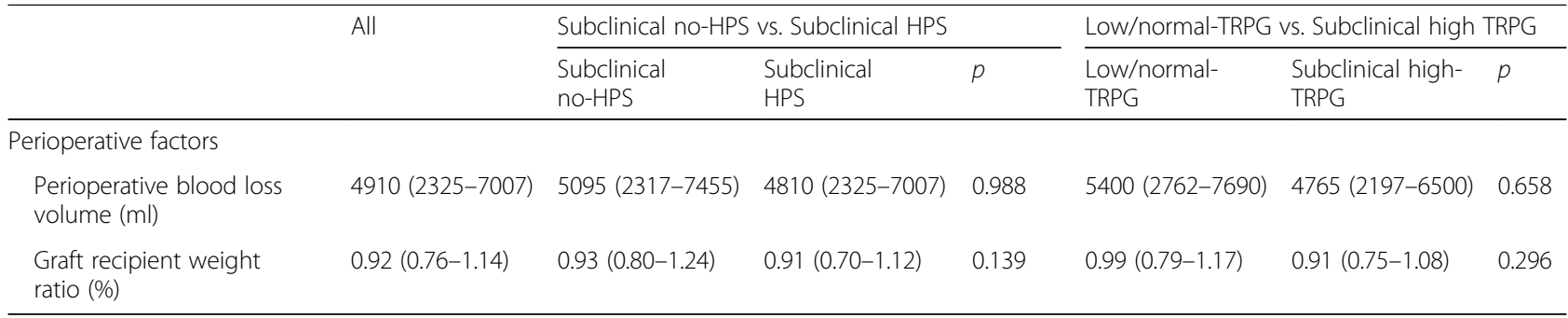

HPS hepatopulmonary syndrome, TRPG tricuspid regurgitation pressure gradient, $B M I$ body mass index, HCV hepatitis $C$ virus-related cirrhosis, HBV hepatitis $B$ virus-related cirrhosis, NASH non-alcoholic steatohepatitis-related cirrhosis, $H C C$ hepatocellular carcinoma, PT-INR prothrombin time international ratio, MELD model for end-stage liver diseases; $\mathrm{AaDO}_{2}$ alveolar-arterial oxygen gradient, $\mathrm{mPAP}-\mathrm{FIO}_{2} 0.6$ mean pulmonary artery pressure measured after general anesthesia with $\mathrm{FIO}_{2} 0.6$ " $p<0.05$

We performed Swan-Ganz catheterization just before the operation after administering general anesthesia for OLT to determine the mPAP. Although $\mathrm{mPAP}>25 \mathrm{mmHg}$ could be diagnosed with definite $\mathrm{POPH}$, the MPAP obtained in the present study was performed under $60 \% \mathrm{O}_{2}$ with mechanical ventilation and was likely affected by this condition. We used these advisory mPAP data, namely mPAP- $\mathrm{FIO}_{2} 0$. 6 , to identify subclinical high TRPG patients in detail.

\section{Post-OLT management of the subjects}

Post-OLT, the patients were treated with a standard immunosuppressive regimen (tacrolimus or cyclosporine A with steroids and/or mycophenolate mofetil). Patients with hepatitis $\mathrm{C}$ recurrence were treated with interferoncontaining regimens, except for five recently transplanted patients who received direct anti-viral agents.

\section{Statistical analyses}

The JMP software program (Version 13.0.0; SAS Institute Inc., Cary, NC, USA) was used to conduct the statistical analyses. Continuous variables were expressed as the median (interquartile range), and the Mann-Whitney $U$-test or chi-squared test was used to compare the parameters between patients with subclinical HPS and subclinical nonHPS or patients with a subclinical high TRPG and subclinical non-high TRPG. A univariate analysis to define the factors affecting the survival was performed by a log-rank test. The factors found to be significant according to a univariate analysis and the widely accepted post-OLT survival-related factor 'MELD score' were used in the multivariate Cox regression analysis. The correlations between the TRPG and mPAP were analyzed using Spearman's rank correlation method. Statistical significance was set at $P<0.05$. The four subgroups were compared using the Mann-Whitney $U$-test or chi-squared test with Bonferroni's correction.

\section{Results}

General characteristics of subclinical HPS and subclinical high TRPG

The baseline liver diseases were 43 hepatitis $C$ virus (HCV)-related cirrhosis, 7 hepatitis B virus (HBV)- related cirrhosis, 13 non-alcoholic steatohepatitis (NASH), and 21 other etiologies. Twenty-nine patients (34.1\%) had hepatocellular carcinoma (HCC) (Table 1). The median model for end-stage liver disease (MELD) score was 16, reflecting decompensated liver cirrhosis. The subclinical HPS patients exhibited no marked clinical differences from the no-HPS patients. However, the subclinical high TRPG patients had a higher MELD score than the low/normal-TRPG patients $(p=0.033)$, indicating a more severe condition of cirrhosis. TTE revealed right ventricular dilatation more frequently in subclinical high TRPG patients than in other patients $(p=0.022)$.

\section{TRPG and mPAP-FIO 20.6}

The TRPG levels observed by TTE and $\mathrm{mPAP}-\mathrm{FIO}_{2} 0.6$ levels observed by Swan-Ganz catheterization were not significantly correlated in our study, although they are widely accepted as correlated (Fig. 1). To determine the reason for this discrepancy, the clinical characteristics were investigated according to the TRPG and mPAP$\mathrm{FIO}_{2} 0.6$ value (Table 2). Patients with a low/normalTRPG and low mPAP-FIO 20.6 (Group $4 ; n=34$ ) were

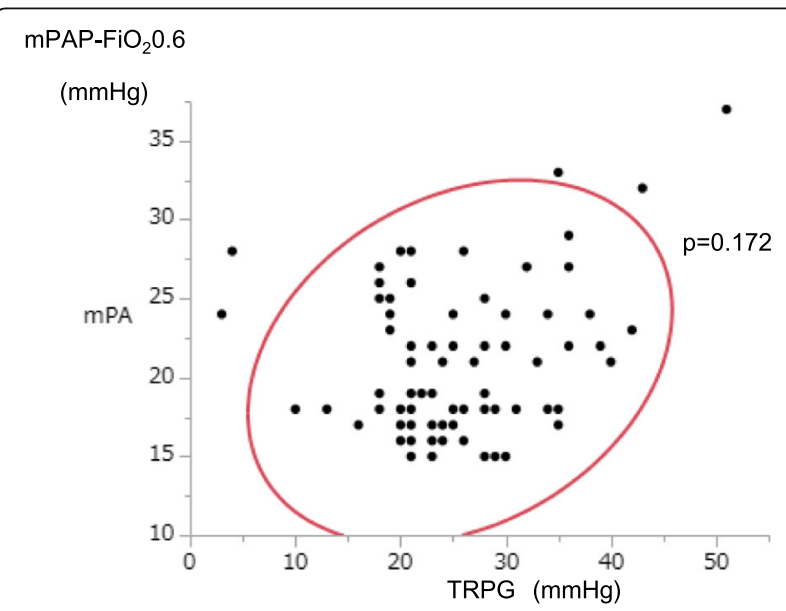

Fig. 1 The correlation between TRPG and mPAP-FIO 20.6 . TRPG; tricuspid regurgitation pressure gradient (TRPG), $\mathrm{mPAP}-\mathrm{FIO}_{2} 0.6$; mean pulmonary artery pressure (mPAP) measured after general anesthesia with $\mathrm{FIO}_{2} 0.6$ 
Table 2 Patient characteristics according to TRPG and mPAP status

\begin{tabular}{|c|c|c|c|c|c|}
\hline & $\begin{array}{l}\text { Group } 1 \\
(n=8)\end{array}$ & $\begin{array}{l}\text { Group } 2 \\
(n=25)\end{array}$ & $\begin{array}{l}\text { Group } 3 \\
(n=7) \\
\end{array}$ & $\begin{array}{l}\text { Group } 4 \\
(n=34) \\
\end{array}$ & $p$ \\
\hline TRPG $\geq 25$ & yes & yes & no & no & \\
\hline mPAP- $\mathrm{FIO}_{2} 0.6>25$ & yes & no & yes & no & \\
\hline Age & $55(48-62)$ & $58(51-61)$ & $59(54-61)$ & $58(49-62)$ & n.s. \\
\hline Donor age & $34(23-39)$ & $43(34-56)$ & $38(33-52)$ & $40(31-54)$ & n.s. \\
\hline MELD & $22(17-25)$ & $16(12-22)$ & $18(12-20)$ & $14(12-17)$ & 0.006 (1 vs 4) \\
\hline Right atrial dilatation (n [\%]) & $5(62 \%)$ & $2(8 \%)$ & $3(42 \%)$ & $4(11 \%)$ & $\begin{array}{l}0.001 \text { (1 vs 2) } \\
0.001 \text { (1 vs 4) }\end{array}$ \\
\hline Right ventricular dilatation (n [\%]) & $3(37 \%)$ & $1(4 \%)$ & 0 & 0 & $\begin{array}{l}0.011 \text { (1 vs } 2 \text { ) } \\
<0.001 \text { (1 vs } 4)\end{array}$ \\
\hline Subclinical HPS (n [\%]) & $3(37 \%)$ & $11(44 \%)$ & $5(71 \%)$ & $6(17 \%)$ & 0.003 (3 vs 4) \\
\hline Graft recipient weight ratio & $1.11(0.95-1.36)$ & $0.88(0.62-0.93)$ & $0.81(0.78-1.19)$ & $0.99(0.79-1.16)$ & 0.015 (1 vs 2) \\
\hline
\end{tabular}

TRPG tricuspid regurgitation pressure gradient, $M P A P-F I O_{2} 0.6$ mean pulmonary artery pressure measured after general anesthesia with FIO $0.6, M^{2} L D$ model for end-stage liver disease, HPS hepato-pulmonary syndrome

p: Wilcoxon rank-sum test with Bonferroni's correction

most frequently identified, exhibiting the lowest MELD score among the groups examined, as expected. Patients with a high TRPG and high-mPAP-FIO ${ }_{2} 0.6$ (Group $1 ; n$ $=8$ ) with clinically definite $\mathrm{PH}$ tended to have a high MELD score ( $p=0.006$ vs Group 4). Patients with a high TRPG and low mPAP-FIO 20.6 (Group 2; $n=25$ ) did not show right heart dilatation. Patients with a low/normalTRPG and high mPAP-FIO 20.6 (Group $3 ; n=7$ ) had the highest rate of positive subclinical HPS ( $p=0.003$ vs Group 4), suggesting that the high congestive pressure might be decreased via right-to-left pulmonary shunting.

Post-LDLT three-month and one-year survival-related factors The pre- and peri-operative risk factors that correlated with the short-term (three-month and one-year) survival are shown in Table 3. A subclinical high TRPG was the only factor found to be correlated with the three-month survival $(p=0.004)$. A higher donor age and MELD score and a subclinical high TRPG were significantly correlated with the one-year survival. However, a multivariate analysis revealed a subclinical high TRPG to be the only significant factor $(\mathrm{p}=0.003)$. The standard cardiac function as reflected by the ejection fraction was not correlated with the survival or post-LDLT renal function.

\section{Post-LDLT 40-month survival-related factors}

The pre- and peri-operative risk factors that correlated with the 40-month survival are shown in Table 3. A higher donor age and MELD score and a subclinical high TRPG were significantly correlated with the 40month survival after OLT. A multivariate analysis revealed a higher donor age and a subclinical high TRPG to be significant factors $(p=0.008$ and 0.012 respectively). The survival rate according to the subclinical high TRPG status is shown in Fig. 2. Subclinical high TRPG patients exhibited both a worse early as well as long- term survival after LDLT than the others $(p=0.002)$. The standard cardiac function as reflected by the ejection fraction was not correlated with the survival or post-LDLT renal function, as in the short-term analysis.

\section{The post-LDLT survival according to TRPG and MPAP- $\mathrm{FIO}_{2} 0.6$ status}

Given that a high TRPG but not a high mPAP-FIO ${ }_{2} 0.6$ was a significant risk factor for the post-LDLT survival, the post-LDLT survival was investigated according to the TRPG and mPAP-FIO ${ }_{2} 0.6$ status in Table 2 (Fig. 3). The post-LDLT survival was worst in Group 2, which had a high TRPG and low mPAP- $\mathrm{FIO}_{2} 0.6$, while a high mPAP was not found to be a significant risk factor in the present study, despite it being widely accepted as such $(p<0.001)$. Group 3 patients with a high mPAP-FIO 20.6 and low TRPG showed a good survival, probably because co-existing HPS released the regurgitation pressure.

\section{Causes of death in those with a subclinical high TRPG}

The causes of death were not significantly different between groups, but the rate of recurrence of $\mathrm{HCV}$ was lower in the subclinical high TRPG patients than in the non-subclinical high TRPG patients $(2 / 10$ vs. 2/4) (Table 4). Four deaths were recorded in patients without a subclinical high TRPG, including two with HCVrelated hepatitis recurrence. Among the patients with subclinical high TRPG, three deaths due to infection, two due to vascular thrombus and HCV recurrence, and one due to small-for-size graft syndrome (graft recipient weight ratio; $0.55 \%$ ) and primary non-functioning of the graft were recorded. These factors other than HCV recurrence may be associated with congestion of the grafted liver. 
Table 3 The survival rate and clinical characteristics

\begin{tabular}{|c|c|c|c|c|c|c|c|c|c|}
\hline & \multirow{2}{*}{$\begin{array}{l}\text { 3-month survival-related factors } \\
\text { Univariate } \\
p \text {-value }\end{array}$} & \multicolumn{4}{|c|}{ 12-month survival-related factors } & \multicolumn{4}{|c|}{ 40-month survival-related factors } \\
\hline & & $\begin{array}{l}\text { Univariate } \\
p \text {-value }\end{array}$ & Risk ratio & $95 \% \mathrm{Cl}$ & $\begin{array}{l}\text { Multivariate } \\
p \text {-value }\end{array}$ & $\begin{array}{l}\text { Univariate } \\
p \text {-value }\end{array}$ & Risk ratio & $95 \% \mathrm{Cl}$ & $\begin{array}{l}\text { Multivariate } \\
p \text {-value }\end{array}$ \\
\hline \multicolumn{10}{|l|}{ Total } \\
\hline \multicolumn{10}{|c|}{ Recipient age (years) } \\
\hline$\geq 58$ & 0.674 & 0.389 & & & & 0.199 & & & \\
\hline \multicolumn{10}{|l|}{$<58$} \\
\hline \multicolumn{10}{|c|}{ Donor age (years) } \\
\hline$\geq 39$ & 0.089 & 0.065 & & & & $0.022^{*}$ & 4.14 & $1.41-15.02$ & $0.008^{*}$ \\
\hline \multicolumn{10}{|l|}{$<39$} \\
\hline \multicolumn{10}{|l|}{ Sex } \\
\hline Male & 0.516 & 0.507 & & & & 0.251 & & & \\
\hline \multicolumn{10}{|c|}{ Female } \\
\hline \multicolumn{10}{|c|}{ Baseline liver disease } \\
\hline $\mathrm{HCV}$ & 0.874 & 0.981 & & & & 0.897 & & & \\
\hline \multicolumn{10}{|l|}{ HBV } \\
\hline \multicolumn{10}{|l|}{ NASH } \\
\hline \multicolumn{10}{|c|}{ Others } \\
\hline \multicolumn{10}{|l|}{$\mathrm{HCC}$} \\
\hline$(+)$ & 0.255 & 0.852 & & & & 0.883 & & & \\
\hline \multicolumn{10}{|l|}{$(-)$} \\
\hline \multicolumn{10}{|l|}{ MELD } \\
\hline$\geq 21$ & 0.150 & $0.006^{*}$ & 1.46 & $0.43-4.59$ & 0.518 & $0.005^{*}$ & 2.23 & $0.72-6.33$ & 0.153 \\
\hline \multicolumn{10}{|l|}{$<21$} \\
\hline \multicolumn{10}{|c|}{ Past history of variceal treatment } \\
\hline$(+)$ & 0.676 & 0.414 & & & & 0.619 & & & \\
\hline \multicolumn{10}{|l|}{$(-)$} \\
\hline \multicolumn{10}{|c|}{$\mathrm{pO}_{2}(\mathrm{mmHg})$} \\
\hline$\geq 83.8$ & 0.640 & 0.324 & & & & 0.155 & & & \\
\hline \multicolumn{10}{|l|}{$<83.8$} \\
\hline $\mathrm{AaDO}_{2}(\mathrm{~m}$ & $\mathrm{hHg})$ & & & & & & & & \\
\hline$\geq 15.9$ & 0.694 & 0.776 & & & & 0.489 & & & \\
\hline$<15.9$ & & & & & & & & & \\
\hline Subclinica & HPS & & & & & & & & \\
\hline$(+)$ & 0.629 & 0.274 & & & & 0.057 & & & \\
\hline$(-)$ & & & & & & & & & \\
\hline Subclinica & high-TRPG & & & & & & & & \\
\hline$(+)$ & $0.004^{*}$ & $0.001^{*}$ & 7.30 & $1.82-48.62$ & $0.003^{*}$ & $0.002^{*}$ & 4.01 & $1.33-14.75$ & $0.012^{*}$ \\
\hline$(-)$ & & & & & & & & & \\
\hline mPAP-FIC & & & & & & & & & \\
\hline$\geq 25$ & 0.660 & 0.152 & & & & 0.097 & & & \\
\hline$<25$ & & & & & & & & & \\
\hline Ejection $\mathrm{f}$ & ction (\%) & & & & & & & & \\
\hline$\geq 71$ & 0.901 & 0.461 & & & & 0.564 & & & \\
\hline$<71$ & & & & & & & & & \\
\hline
\end{tabular}


Table 3 The survival rate and clinical characteristics (Continued)

\begin{tabular}{|c|c|c|c|c|c|c|c|c|c|}
\hline & \multirow{2}{*}{$\begin{array}{l}\text { 3-month survival-related factors } \\
\text { Univariate } \\
p \text {-value }\end{array}$} & \multicolumn{4}{|c|}{ 12-month survival-related factors } & \multicolumn{4}{|c|}{ 40-month survival-related factors } \\
\hline & & $\begin{array}{l}\text { Univariate } \\
p \text {-value }\end{array}$ & Risk ratio & $95 \% \mathrm{Cl}$ & $\begin{array}{l}\text { Multivariate } \\
p \text {-value }\end{array}$ & $\begin{array}{l}\text { Univariate } \\
p \text {-value }\end{array}$ & Risk ratio & $95 \% \mathrm{Cl}$ & $\begin{array}{l}\text { Multivariate } \\
p \text {-value }\end{array}$ \\
\hline \multicolumn{10}{|c|}{ Left atrial diameter (mm) } \\
\hline$\geq 38.0$ & 0.432 & 0.982 & & & & 0.544 & & & \\
\hline \multicolumn{10}{|l|}{$<38.0$} \\
\hline \multicolumn{10}{|c|}{ Perioperative blood loss volume (ml) } \\
\hline$\geq 4910$ & 0.092 & 0.242 & & & & 0.295 & & & \\
\hline \multicolumn{10}{|l|}{$<4910$} \\
\hline \multicolumn{10}{|c|}{ Graft recipient weight ratio } \\
\hline$\geq 0.92$ & 0.258 & 0.057 & & & & 0.209 & & & \\
\hline$<0.92$ & & & & & & & & & \\
\hline
\end{tabular}

HCV hepatitis $C$ virus-related cirrhosis, HBV hepatitis B virus-related cirrhosis, NASH non-alcoholic steatohepatitis-related cirrhosis, $H C C$ hepatocellular carcinoma, MELD model for end-stage liver disease, $\mathrm{AaDO}_{2}$ alveolar-arterial oxygen gradient, HPS hepato-pulmonary syndrome, TRPG tricuspid regurgitation pressure gradient, $\mathrm{mPAP}_{*} \mathrm{FIO}_{2} \mathrm{O} .6$ mean pulmonary artery pressure measured after general anesthesia with $\mathrm{FIO}_{2} 0.6$ ${ }^{*} p<0.05$

\section{Discussion}

In the present study, a high TRPG was a definite survivaldefining factor after LDLT that might be able to be controlled before or during operation. Even in patients with a high mPAP-FIO ${ }_{2} 0.6$, the co-existence of subclinical HPS might reduce the TRPG, thus resulting in a good prognosis. The TRPG but not $\mathrm{mPAP}-\mathrm{FIO}_{2} 0.6$ was a critical factor that may reflect the pressure directed to the grafted small living-donor liver. Given that this study was retrospective and the sample size was relatively small, larger prospective studies to confirm the present results are needed.

Reported factors associated with a worse survival after primary DDLT include a high MELD score, HCV positivity, aged recipient, aged donor [10], mechanical ventilation before OLT, and dialysis [11]. Although the present data did not include the hepatic venous pressure gradient (HVPG), which is an accurate reflection of the portal pressure gradient, we included the Child-Pugh score, MELD score and the history of variceal treatment to assess the severity of cirrhosis. As survival-related factors after LDLT, small-for-size graft syndrome is an additional important factor [12]. The present investigation indicated that a pre-LDLT subclinical high TRPG was an independent strong survival-determining factor after LDLT. Although not all patients with a subclinical high TRPG exhibited PH, congestive pressure to the grafted liver likely affected the small living donor graft function recovery post-LDLT.

In LDLT settings, graft blood flow in the initial few weeks after surgery has been reported to influence the

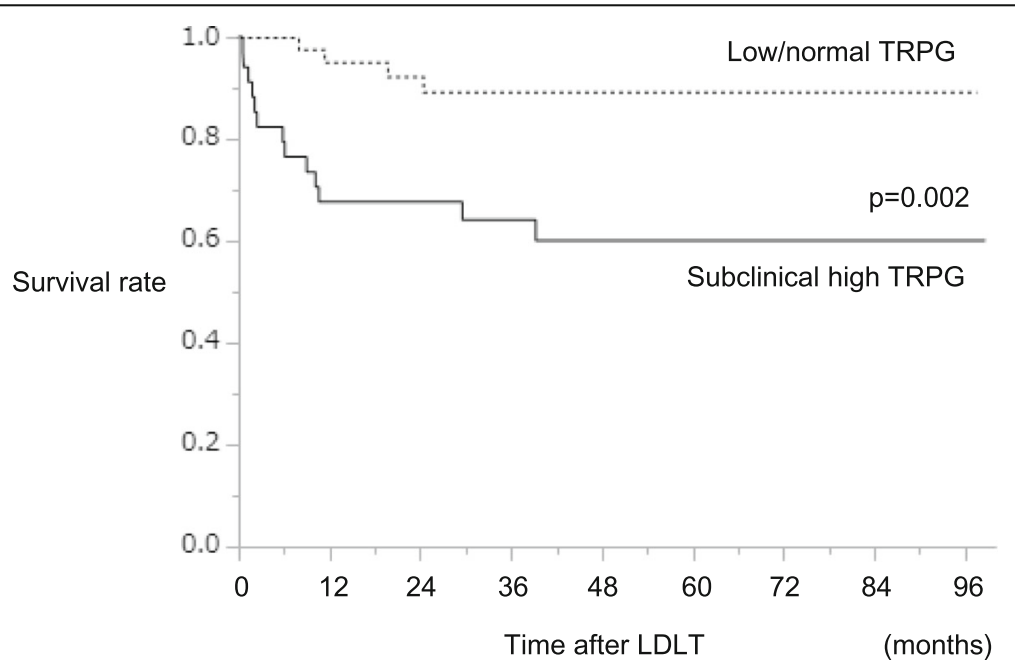

Fig. 2 The survival rate according to the existence of subclinical high TRPG. The 40-month survival rate. The solid line indicates a subclinical high TRPG, and the dashed line indicates a non-subclinical high TRPG 


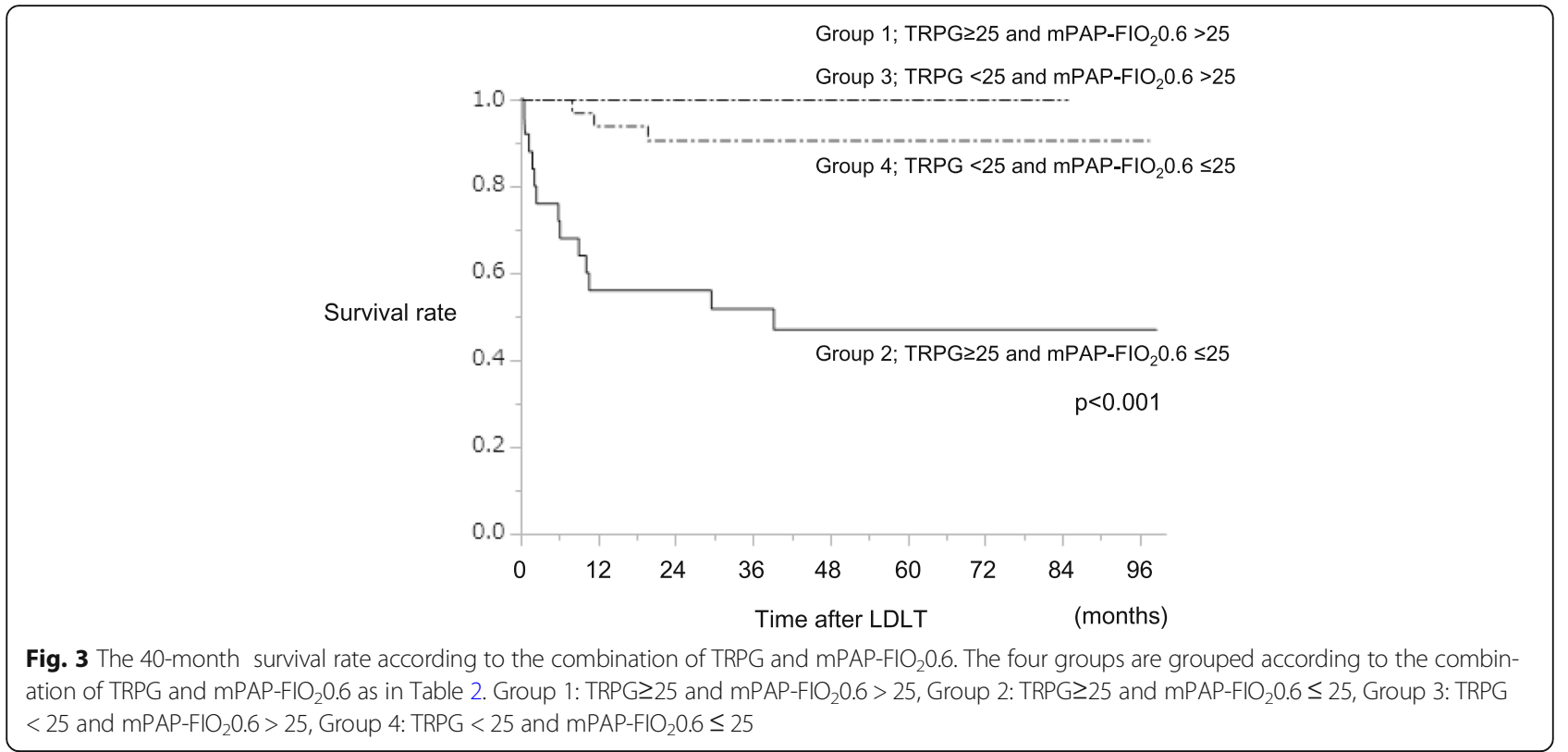

overall outcome of small-for-size liver graft OLT. Poor venous outflow and resulting hepatic congestion have been shown to be strong factors for a poor graft function [13]. Several vascular surgical techniques to reduce hepatic venous congestion have been adopted to improve the living donor graft survival $[14,15]$. These findings indicate that hepatic venous congestion and the resulting graft congestion are relatively frequent prognosisdefining factors in LDLT, although such congestion is not usually severely problematic in DDLT. The present results suggested that a high mPAP measured after general anesthesia did not affect the outcome post-LDLT; however, a subclinical high TRPG measured by TTE proved to be a strong predictor of a bad outcome. The most frequent causes of deaths in the subclinical high TRPG patients were infection and secondly vascular thrombus. Bacterial translocation from the intestine could be induced by pressure at the graft portal tract resulting in severe infection, and vascular thrombus could also be induced by pressure at the graft. These frequent causes of death in the subclinical high TRPG patients all involved, albeit indirectly, high pressure being applied to the grafts.

TRPG measured by TTE is usually positively correlated with MPAP measured by right heart catheterization [16].
However, several reports have published findings denying such a correlation [17, 18]. One analysis reported that over- and underestimation occurred equally frequently with TTE [19]. Another report stated that TTE underestimated $\mathrm{PH}$ more often than catheterization, especially in patients with RV enlargement or right heart failure [20]. However, a different report claimed that severe TR could induce altered right heart hemodynamics, resulting in the overestimation of PH [21]. These conflicting findings are partly because TRPG measures the indirect peripheral pulmonary arterial pressure to the right ventricle and right atrium, while mPAP measures the microvessel-level central pulmonary arterial pressure. Our present results indicated no significant correlation between mPAP-FIO ${ }_{2} 0.6$ and TRPG. Given that $\mathrm{O}_{2}$ administration is an accepted supportive therapy for $\mathrm{PH}$, the present mPAP-FIO ${ }_{2} 0.6$ may be lower than the mPAP measured by standard right heart catheterization used as a diagnostic marker for PH. Although the present mPAP$\mathrm{FIO}_{2} 0.6$ is different from the mPAP measured by the standard method, all of our patients were in a similar medical condition, and therefore the investigation of the correlation in this population was deemed acceptable. The difference between standard MPAP and mPAP$\mathrm{FIO}_{2} 0.6$ cannot be determined. The clinical impact of

Table 4 Causes of deaths according to subclinical high TRPG

\begin{tabular}{|c|c|c|c|c|c|c|}
\hline & Small-for-size graft syndrome & Primary non-functioning & Vascular thrombus & Infection & $\mathrm{HCV}$ recurrence & Others \\
\hline \multicolumn{7}{|c|}{ Subclinical high TRPG } \\
\hline$(+)$ & 1 & 1 & 2 & 3 & 2 & 1 \\
\hline$(-)$ & 0 & 0 & 0 & 1 & 2 & 1 \\
\hline
\end{tabular}

TRPG tricuspid regurgitation pressure gradient, $H C V$ hepatitis $\mathrm{C}$ virus 
these values on the post-LDLT survival also differed, as a higher TRPG was significantly correlated with the outcome, while a higher mPAP- $\mathrm{FIO}_{2} 0.6$ was not. The patients included in our present study exhibited a relatively large left atrium with high $\mathrm{AaDO}_{2}$ compared with the normal range observed in the Japanese population, indicating right-to-left shunt predominance with subclinical HPS. The co-existence of subclinical HPS was particularly predominant in Group 3, indicating that TRPG is not high even when mPAP is high. The pressure against the grafted liver is reflected by the TRPG, not by the mPAP, as the pressure may be reduced due to pulmonary arterial bypass with HPS. Given the small sample size, especially in Group 1 and 3, larger studies are needed to confirm this possibility.

HPS is more frequently found than POPH and has been acknowledged as a life-threatening complication; however, this condition can be resolved with OLT [22]. The pathophysiology of this condition is considered to be pulmonary vessel dilatation due to the easily identified vascular dilation-related hormonal changes in liver cirrhosis [1]. As we did not perform TTE with a bubble study, which is the standard sensitive imaging test for identifying intra-pulmonary vascular shunting, we diagnosed only one definite HPS patient by lung perfusion scintigraphy. However, the subclinical HPS patients who clinically exhibited HPS phenomena accounted for 33\% of the included subjects. This subclinical HPS condition is frequently accompanied by end-stage liver disease. In our present analysis, the Group 3 patients with a relatively high mPAP and a low TRPG exhibited a higher frequency of subclinical HPS than the other groups. The definite POPH with definite HPS combination has been reported to be associated with a poor 1-year survival rate of $68 \%$, while POPH alone is associated with a $91 \%$ survival rate excluding OLT recipients [23]. The post-OLT survival was worse in POPH patients with HPS (5 of 5 dead) than in patients with POPH alone (3 of 3 alive). However, our present results concerning the post-LDLT survival indicated the opposite effect. These patients may not be very sick, as they exhibited only "subclinical" high TRPG and HPS. They may therefore be in good enough health to benefit from HPS, although their mPAP- $\mathrm{FIO}_{2} 0.6$ values were high. Under these conditions, regurgitation pressure from the pulmonary artery might escape via an intra-pulmonary shunt.

The cardio-pulmonary clinical condition of Group 2, who had a high TRPG and low MPAP, was associated with the worst outcome of the examined groups. This condition is similar to left-to-right shunting or right heart failure although not clinically evident. In addition, the Group 2 patients exhibited a lower frequency of RA dilatation than those in Group 1, showing a high TR pressure without RA dilatation, which indicated a strong pressure directed to the grafted liver. RA dilatation may relieve the direct pressure to the graft.

\section{Conclusion}

TRPG as assessed by TTE may be more useful than mPAP by pre-operational right heart catheterization under $\mathrm{FIO}_{2} 0.6$ for predicting the post-OLT survival. A high TRPG, even below the limit of $\mathrm{PH}$, may reflect pressure to the grafted liver that might be critical for relatively small-for-size LDLT. Given that this study was retrospective and the sample size was relatively small, larger prospective studies to confirm the present results are needed. When patients with a high TRPG undergo LDLT, the administration of therapies to reduce the TRPG should be considered.

\begin{abstract}
Abbreviations
[99 m]Tc-MAA: Technetium-99 m-labeled macroaggregated albumin; $\mathrm{AaDO}_{2}$ : Alveolar-arterial oxygen gradient; DDLT: Deceased donor LT; HBV: Hepatitis B virus-related cirrhosis; HCC: Hepatocellular carcinoma; HCV: Hepatitis C virus-related cirrhosis; HPS: Hepatopulmonary syndrome; LDLT: Living donor liver transplantation; MELD: Model for end stage liver disease; mPAP: Mean pulmonary artery pressure; $\mathrm{mPAP}-\mathrm{FIO}_{2} 0.6$ : MPAP measured after general anesthesia with $\mathrm{FIO}_{2} 0.6$; NASH: Non-alcoholic steatohepatitis; OLT: Orthotopic liver transplantation; PCWP: Pulmonary capillary wedge pressure; $\mathrm{PH}$ : Pulmonary hypertension;

POPH: Portopulmonary hypertension; RA: Right atrium; RV: Right ventricle; TR: Tricuspid regurgitation; TRPG: Tricuspid regurgitation pressure gradient; TTE: Transthoracic echocardiography
\end{abstract}

\section{Acknowledgements}

We thank Mrs. Mari Yoshida and Chisato Arimori for supporting the patients as transplant coordinators. We thank Mrs. Ishii for her help with the data management.

\section{Availability of data and materials}

The datasets analyzed during the current study are not publicly available due to the clinical data are included but are available from the author Akinobu Takaki on reasonable request.

\section{Authors' contributions}

All authors have read and approved the manuscript. YS: acquisition, analysis and interpretation of data, AT: study concept and design, YU: acquisition, analysis and interpretation of data, TM; acquisition, analysis and interpretation of data, TY: acquisition of data, AO: acquisition of data, RK: acquisition of data, $\mathrm{KN}$ : acquisition, analysis and interpretation of data, RY: acquisition of data, DN: acquisition of data, TK: acquisition of data, KT: acquisition of data, TA: acquisition of data, NW: acquisition of data, YT: acquisition of data, KK: acquisition of data, Fl: acquisition of data, $\mathrm{HO}$ : acquisition of data, HS: acquisition of data, SN: acquisition of data, HM: study supervision, HI: study supervision, TF: study supervision, TY: critical revision of the manuscript for important intellectual content, HO: study supervision.

\section{Ethics approval and consent to participate}

This study was approved by the ethics committee of Okayama University Hospital. The project number is Ken1607-005.

Informed consent was obtained from each patient included in the study, and the study protocol conformed to the ethical guidelines of the 1975 Declaration of Helsinki as reflected in approval by the ethics committee at Okayama University Hospital. After obtaining the patients' written informed consent, a detailed medical questionnaire was completed by the doctors.

\section{Competing interests}

The authors declare that they have no competing interests. 


\section{Publisher's Note}

Springer Nature remains neutral with regard to jurisdictional claims in published maps and institutional affiliations.

\section{Author details}

'Department of Gastroenterology and Hepatology, Okayama University Graduate School of Medicine, Dentistry and Pharmaceutical Sciences, 2-5-1 Shikata-cho, Kita-ku, Okayama 700-8558, Japan. ${ }^{2}$ Department of Gastroenterological Surgery, Transplant and Surgical Oncology, Okayama University Graduate School of Medicine, Dentistry and Pharmaceutical Sciences, 2-5-1 Shikata-cho, Kita-ku, Okayama 700-8558, Japan. ${ }^{3}$ Department of Anesthesiology and Resuscitology, Okayama University Graduate School of Medicine, Dentistry and Pharmaceutical Sciences, 2-5-1 Shikata-cho, Kita-ku, Okayama 700-8558, Japan. ${ }^{4}$ Department of Cardiovascular Medicine, Okayama University Graduate School of Medicine, Dentistry and Pharmaceutical Sciences, 2-5-1 Shikata-cho, Kita-ku, Okayama 700-8558, Japan.

Received: 10 November 2017 Accepted: 1 May 2018

Published online: 15 May 2018

\section{References}

1. Porres-Aguilar M, Altamirano JT, Torre-Delgadillo A, Charlton MR, DuarteRojo A. Portopulmonary hypertension and hepatopulmonary syndrome: a clinician-oriented overview. Eur Respir Rev. 2012;21:223-33.

2. Goldberg DS, Fallon MB. The art and science of diagnosing and treating lung and heart disease secondary to liver disease. Clin Gastroentero Hepatol. 2015;13:2118-27.

3. Fallon MB, Krowka MJ, Brown RS, et al. Impact of hepatopulmonary syndrome on quality of life and survival in liver transplant candidates. Gastroenterology. 2008;135:1168-75.

4. Krowka MJ, Fallon MB, Kawut SM, et al. International liver transplant society practice guidelines: diagnosis and management of hepatopulmonary syndrome and portopulmonary hypertension. Transplantation. 2016;100: 1440-52.

5. Krowka MJ, Plevak DJ, Findlay JY, Rosen CB, Wiesner RH, Krom RA. Pulmonary hemodynamics and perioperative cardiopulmonary-related mortality in patients with portopulmonary hypertension undergoing liver transplantation. Liver Transpl. 2000;6:443-50.

6. Starkel P, Vera A, Gunson B, Mutimer D. Outcome of liver transplantation for patients with pulmonary hypertension. Liver Transpl. 2002;8:382-8.

7. Galie N, Humbert M, Vachiery JL, et al. 2015 ESC/ERS guidelines for the diagnosis and treatment of pulmonary hypertension: the joint task force for the diagnosis and treatment of pulmonary hypertension of the European Society of Cardiology (ESC) and the European Respiratory Society (ERS): endorsed by: Association for European Paediatric and Congenital Cardiology (AEPC), International Society for Heart and Lung Transplantation (ISHLT). Eur Heart J. 2016:37:67-119.

8. Yock PG, Popp RL. Noninvasive estimation of right ventricular systolic pressure by Doppler ultrasound in patients with tricuspid regurgitation. Circulation. 1984;70:657-62.

9. Rodriguez-Roisin R, Krowka MJ, Herve P, Fallon MB. Pulmonary-hepatic vascular disorders (PHD). Eur Respir J. 2004;24:861-80.

10. Habib S, Berk B, Chang CC, et al. MELD and prediction of post-liver transplantation survival. Liver Transpl. 2006;12:440-7.

11. Desai NM, Mange KC, Crawford MD, et al. Predicting outcome after liver transplantation: utility of the model for end-stage liver disease and a newly derived discrimination function. Transplantation. 2004;77:99-106.

12. Yoshizumi T, Taketomi A, Uchiyama H, et al. Graft size, donor age, and patient status are the indicators of early graft function after living donor liver transplantation. Liver Transpl. 2008;14:1007-13.

13. Emond JC, Heffron TG, Whitington PF, Broelsch CE. Reconstruction of the hepatic vein in reduced size hepatic transplantation. Surg Gynecol Obstet. 1993;176:11-7

14. Yamazaki S, Takayama T, Makuuchi M. The technical advance and impact of caudate lobe venous reconstruction in left liver: additional safety for livingrelated donor liver transplantation. Transpl Int. 2010;23:345-9.

15. Sugawara Y, Makuuchi M, Imamura H, Kaneko J, Ohkubo T, Kokudo N. Outflow reconstruction in recipients of right liver graft from living donors. Liver Transpl. 2002;8:167-8.
16. Finkelhor RS, Lewis SA, Pillai D. Limitations and strengths of doppler/echo pulmonary artery systolic pressure-right heart catheterization correlations: a systematic literature review. Echocardiography. 2015;32:10-8.

17. Testani JM, St John Sutton MG, Wiegers SE, Khera AV, Shannon RP, Kirkpatrick JN. Accuracy of noninvasively determined pulmonary artery systolic pressure. Am J Cardiol. 2010;105:1192-7.

18. Hioka T, Kaga S, Mikami T, et al. Overestimation by echocardiography of the peak systolic pressure gradient between the right ventricle and right atrium due to tricuspid regurgitation and the usefulness of the early diastolic transpulmonary valve pressure gradient for estimating pulmonary artery pressure. Heart Vessels. 2017;32(7):833-42.

19. Farber HW, Foreman AJ, Miller DP, McGoon MD. REVEAL registry: correlation of right heart catheterization and echocardiography in patients with pulmonary arterial hypertension. Congest Heart Fail. 2011;17:56-64.

20. Fisher MR, Forfia PR, Chamera E, et al. Accuracy of Doppler echocardiography in the hemodynamic assessment of pulmonary hypertension. Am J Respir Crit Care Med. 2009;179:615-21.

21. Ozpelit E, Akdeniz B, Ozpelit EM, et al. Impact of severe tricuspid regurgitation on accuracy of echocardiographic pulmonary artery systolic pressure estimation. Echocardiography. 2015;32:1483-90.

22. Tanikella R, Fallon MB. Hepatopulmonary syndrome and liver transplantation: who, when, and where? Hepatology. 2013;57:2097-9.

23. Fussner LA, lyer VN, Cartin-Ceba R, Lin G, Watt KD, Krowka MJ. Intrapulmonary vascular dilatations are common in portopulmonary hypertension and may be associated with decreased survival. Liver Transpl. 2015;21:1355-64.

\section{Ready to submit your research? Choose BMC and benefit from:}

- fast, convenient online submission

- thorough peer review by experienced researchers in your field

- rapid publication on acceptance

- support for research data, including large and complex data types

- gold Open Access which fosters wider collaboration and increased citations

- maximum visibility for your research: over $100 \mathrm{M}$ website views per year

At BMC, research is always in progress.

Learn more biomedcentral.com/submissions 